International Institute for Population Sciences

Mumbai-400088

Email: datacenter@iipsindia.ac.in / Phone: 022-42372466
Longitudinal

Ageing Study

in India

(LASI)

\title{
Data Request Form for
}

Longitudinal Ageing Study in India (LASI), Wave - I, 2017-18 *

Name:

Designation

Institution Name

Email

Phone/Mobile Number

Address

Country

Purpose of the

requesting the Dataset

(

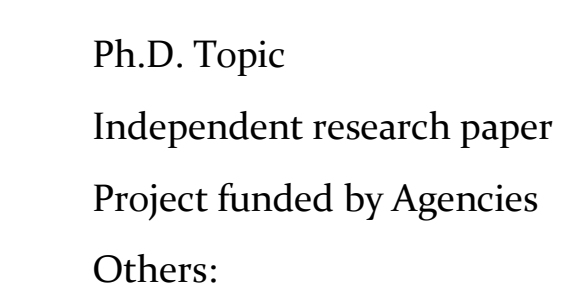

Format of Dataset

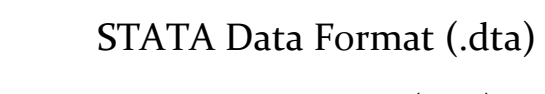

SPSS Data Format (.sav)

Data request for

$\square$ HH_Roster, HH, IND \& BM Dataset
$\square$ CV $(\mathrm{HH})$ Member file $\square$ HH Death Member file
$\square$ Community Dataset
$\square$ Metro-City Data

Please explain the

research topic within 500

words

Attach the proposal of study with specific objectives and data requirement.

A valid Identity proof issued by the competent authority is mandatory to be attached with this form.

Date:

Place: 